\title{
Responsabilidade civil do médico e a inversão do pensamento jurídico sobre o tipo da atividade
}

\author{
Liability of the physician and the turnaround of legal thinking about the kind of activity
}

\author{
FERNANDO CORDEIRO' ${ }^{1}$, SAMUEL MENDONÇA² ${ }^{2}$ JOANNA PAES DE BARROS E OLIVEIRA ${ }^{3}$, \\ VANESSA FABIULA PANCIONI NOGUEIRA ${ }^{4}$
}

\begin{abstract}
${ }^{1}$ Professor Titular de Clínica Cirúrgica da Faculdade de Medicina da Pontifica Universidade Católica de Campinas (PUC-Campinas); Aluno do Curso de Direito da Faculdade de Direito da PUC-Campinas. ${ }^{2}$ Professor de Metodologia da Pesquisa Jurídica B do Curso de Direito da Faculdade de Direito da PUC-Campinas. ${ }^{3}$ Professora de Direito Civil do Curso de Direito da Faculdade de Direito da PUC-Campinas. ${ }^{4}$ Professora de Direito do Curso de Direito da Faculdade Metrocamp de Campinas.
\end{abstract}

CORDEIRO F, MENDONÇA S, OLIVEIRA JPDB, NOGUEIRA VFP. Responsabilidade civil do médico e a inversão do pensamento jurídico sobre o tipo da atividade. Rev bras Coloproct, 2011;31(1): 58-63.

RESUMO: Sempre que uma ação causar dano a outra pessoa e houver nexo causal, isto é, quando o resultado observado pela prática desta ação estiver, diretamente ou não, relacionado, caberá a obrigação de ressarcir à vítima, um valor referente ao seu dano. Esta normatização, Responsabilidade Civil, tem como fundamento o princípio da culpa, quando subjetiva (que tem necessidade de um ato ou omissão de violar o direito de uma segunda pessoa, o dano produzido por este ato, a responsabilidade de causalidade entre o ato e o dano e, finalmente, a culpa) e o princípio do risco quando objetivo (que não necessita de culpa, já que se baseia na teoria do risco, presumindo-a, independentemente de ter ou não agido com esta intenção). Enquanto Responsabilidade Civil Contratual, duas são as obrigações de um profissional: a de resultado, ou seja, a de alcançar determinado objetivo ou fim, e a de meio, ou seja, a obrigação de empregar todos os meios para consecução de seu objetivo. No Código de Proteção e Defesa do Consumidor (Lei 8.078, de 11 de setembro de 1990), a responsabilidade objetiva deve ser empregada a todos os prestadores de serviço à exceção da classe dos profissionais liberais, médicos e advogados, por realizarem suas atividades principalmente como sendo de meios e, portanto, considerada subjetiva. Em algumas situações, o Direito entende que a Responsabilidade deve ser objetiva, ou seja, quando ficar consubstanciado uma promessa de resultado. As peças publicitárias têm tido o poder de evocar estas equivocadas situações. O objetivo principal deste trabalho é mostrar, aos profissionais do Direito em geral e aos médicos em particular, quais são os fenômenos que criaram o desvio da norma. A Responsabilidade Civil Subjetiva se encontra amparada no Código Civil, em seu Art. 186 e no caput do Art. 927 , enquanto a Objetiva é observada no Art. 927, § único. Desta forma, ao relacionar os textos da literatura jurídica e os dados do Conselho Regional de Medicina do Estado de São Paulo, quanto a peças publicitárias e sindicâncias instauradas sobre este sujeito, os autores pretendem demonstrar a relação causal desta nova forma de pensar.

Palavras-chave: responsabilidade civil médica, responsabilidade subjetiva, responsabilidade objetiva.

\section{INTRODUÇÃO}

Não cabe dúvida no Direito Civil que toda vez que uma ação causar dano a outra pessoa, sendo estabelecido um nexo causal, isto é, quando o resultado observado pela prática de determinada ação estiver direta ou indiretamente relacionado, caberá àquele que praticou a ação a obrigação de ressarcir ao outro, ou seja, àquele que foi vítima do ato realizado, um valor referente ao seu dano, porém estas regras para o estabelecimento do nexo causal não ficam claramente explicitadas, independentemente de serem objetivas ou subjetivas.

A normatização denominada Responsabilidade Civil tem para o Direito Brasileiro, como regra, o

Trabalho realizado na Faculdade de Medicina e na Faculdade de Direito da Pontificia Universidade Católica de Campinas.

Recebido em: $14 / 09 / 2010$

Aprovado em: 14/04/2011 
fundamento do princípio da culpa. Esta, por sua vez, segundo Mário Moacyr Porto, "é o desvio de um modelo ideal de conduta que implica a avaliação dos fatores subjetivos que conduzem o agente à prática do ato lesivo"1.

Duas são as teorias de Responsabilidade Civil: a subjetiva e a objetiva. À primeira impõe-se a necessidade de um ato ou omissão que viole o direito de uma segunda pessoa, o dano produzido por este ato ou omissão, a responsabilidade de causalidade entre o ato ou omissão e o dano e, finalmente, a culpa ${ }^{2}$. À segunda, ou seja, a responsabilidade objetiva, subtrai-se a culpa, ou seja, o causador da ação responde sem culpa, pois a norma se baseia na teoria do risco, a qual menciona que o prejuízo deve ser atribuído ao seu autor e reparado por quem o causou, independentemente de ter, ou não, agido com intenção. Responsável é aquele que causou o dano, não importando o que ele tenha a dizer.

Para identificar a responsabilidade objetiva, utiliza-se a presunção de culpa, isto é, mesmo que não o acredite, a reclamada parte do pressuposto de uma responsabilidade inequívoca e não da necessidade de se the apurar culpa.

Enquanto Responsabilidade Civil Contratual, duas são as obrigações de um profissional: a de resultado, ou seja, a obrigação de alcançar determinado objetivo ou resultado, sem o qual extingue-se a relação contratual, e a de meio, ou seja, obrigação de empregar os modos para consecução de seu objetivo.

Surge agora um novo complicador, quando coloca-se uma classe profissional e suas responsabilidades frente àquele que o procurou para remediar um problema estabelecido: o profissional médico.

No Código de Proteção e Defesa do Consumidor ${ }^{3}$ (Lei 8078, de 11 de setembro de 1990), esta responsabilidade, classificada como objetiva, deve ser empregada a todos os prestadores de serviço com exceção à classe dos profissionais liberais, por realizarem suas atividades principalmente como sendo de meios e, portanto, considera-se responsabilidade subjetiva (Art.14, §4).

Porém, muitas são as ações e sentenças que determinam o contrário, imputando ao médico um compromisso com o resultado, principalmente na área da estética, considerando esta responsabilidade como sendo objetiva.

Assim sendo, qual das definições de responsabilidade civil cabe, à luz do Direito, aos profissionais mé- dicos, subjetiva ou objetiva? Como deve se comportar o prestador de serviço médico frente ao seu paciente à luz do Código de Proteção e Defesa do Consumidor?

O objetivo geral pretendido neste exercício é compreender as Normas Jurídicas referentes às relações contratuais e suas responsabilidades: Código Civil Brasileiro e Código de Proteção e Defesa do Consumidor.

Quanto aos objetivos específicos, estes compreendem o entendimento das bases doutrinárias de obrigações e responsabilidades civis (subjetiva ou objetiva), relacionando-as com as normas específicas dos profissionais liberais como prestadores de serviços e com a obrigação de meio e não de fins, e em quais situações haveria a modificação destas obrigações.

Pretende-se, também, mostrar em quais eventos, um profissional passa a ter a responsabilidade civil vista como sendo objetiva, sem necessidade da prova de culpa similarmente a uma eventual promessa de resultado. Desta maneira, auxiliando estes profissionais a não incorrerem no erro da promessa e auxiliando os agentes do Direito a entenderem que esta ação médica não é um ato geral, mas, particular de alguns profissionais, os quais, excedendo seu direito de publicitar suas ações colaboram com a deturpação do pensamento jurídico atual.

Este trabalho vem sendo realizado em colaboração com o Conselho Regional de Medicina do Estado de São Paulo, por meio da Comissão de Divulgação de Assuntos Médicos, sob a responsabilidade do Conselheiro Doutor Lavínio Nilton Camarim, o qual, nos últimos anos, esmera-se em coibir as publicidades desmesuradas e o equivocado entendimento de que todas as frutas do pomar estão podres. Em decorrência desse fato, a identificação das repercussões legais destes meandros da vida jurídica fez com que houvesse a oportunidade de, à luz dos textos legais, tais como os Códigos Civil e de Proteção e Defesa do Consumidor, das jurisprudências do Supremo Tribunal de Justiça e dos dados do Conselho Regional de Medicina do Estado de São Paulo, quanto ao número de sindicâncias instauradas, seja por solicitação da sociedade civil organizada ou por parte do próprio Conselho, refletir sobre o assunto no sentido de impedir que o olhar normativo seja revertido.

O trabalho apresenta as definições legais sobre Responsabilidade Civil e os levantamentos, baseados em dados do Conselho Regional de Medicina do Estado de São Paulo, finalizando com uma discussão sobre o tema. 


\section{DEFINIÇÕES LEGAIS DAS RESPONSABILIDADES CIVIS}

Enquanto Responsabilidade Civil Contratual, duas são as obrigações do profissional, a de resultado, ou seja, a obrigação de alcançar determinado objetivo ou resultado, sem o qual se ext ingue a relação contratual e a de meio, ou seja, obrigação de empregar todos os meios para consecução de seu objetivo frente ao contratante.

A Responsabilidade Civil Subjetiva se encontra amparada no Código Civil ${ }^{4}$, em seu Art. 186 e no caput do Art. 927 que diz, como regra geral, "aquele que, por ação ou omissão voluntária, negligência ou imprudência, violar direito e causar dano a outrem, ainda que exclusivamente moral, comete ato ilícito"; "aquele que, por ato ilícito, causar dano a outrem, fica obrigado a repará-lo".

\section{ATO ILÍCITO nexo causal DANO \\ (responsabilidade subjetiva)}

Já a Responsabilidade Civil Objetiva, segundo a Teoria da Responsabilidade Objetiva, encontra amparo neste mesmo Código Civil ${ }^{4}$, no Art. 927 § Único, o qual menciona que: "§ Único - Haverá obrigação de reparar o dano, independentemente de culpa, nos casos especificados em lei, ou quando a atividade normalmente desenvolvida pelo autor do dano implicar, por sua natureza, risco para os direitos de outrem".

\section{ATO LÍCITO nexo causal DANO \\ (responsabilidade subjetiva - Teoria do Risco)}

Segundo o artigo 927, não há necessidade da demonstração de culpa tendo em vista que a atividade apresenta intrinsecamente um risco a outros.

No Código de Proteção e Defesa do Consumidor ${ }^{3}$, em seu Art. 14, $4^{\circ}$, lê-se: "A responsabilidade pessoal dos profissionais liberais será apurada mediante a verificação de culpa". Portanto, há que se demonstrar que o mesmo agiu sem dolo ou com negligência, imprudência ou imperícia a estes profissionais.

\section{LEVANTAMENTOS CONSELHAIS E JURISPRUDENCIAIS}

Apesar do que foi anteriormente referido, escrito no Código de Proteção e Defesa do Consumidor, Lei $8.078(11 / 09 / 1990)$, no Art. $14, \S 4^{\circ}$, que a responsabilidade civil médica é subjetiva por se tratar de uma atividade de meios e o que pensa a maioria dos juristas concordes com esta posição, no que tange à medicina dita estética (cirurgia plástica embelezadora, dermatologia, cirurgia bariátrica etc.), é crescente o lugar comum de que esta seria uma atividade com intenção claramente de resultados. Advogados, juízes e demais operadores do Direito, bem como a população em geral, creditam ao profissional liberal desta área uma responsabilidade dita objetiva, por entenderem que o contrato entre as partes envolvidas tem como objeto final o resultado de um embelezamento do paciente.

Isto tem promovido intenso movimento de demandas judiciais no sentido da reparação do eventual dano apelado, corroborada pelo incremento de demandas também na esfera ética.

Em recente levantamento realizado no Conselho Regional de Medicina do Estado de São Paulo, junto à CODAME, no período de 2000 a 2007, observou-se a abertura de sindicâncias para apuração de indícios de ilícitos éticos por alegação de propostas de resultados mal-sucedidos em número superior a 1.500.

A Tabela 1 apresenta de maneira isolada e por ano, o quão importante é o crescimento destas sindicâncias nas áreas supracitadas.

Mesmo não sendo ainda um Processo Ético Profissional, a Sindicância, como parte inicial da

Tabela 1. Número de sindicâncias por ano e por especialidade médica.

\begin{tabular}{lcccccccc}
\hline & 2000 & 2001 & 2002 & 2003 & 2004 & 2005 & 2006 & 2007 \\
\hline Cirurgia plástica & 67 & 213 & 103 & 72 & 96 & 85 & 417 & 212 \\
Dermatologia & 17 & 36 & 31 & 13 & 22 & 36 & 78 & 74 \\
Cirurgia bariátrica & 0 & 0 & 1 & 2 & 1 & 2 & 5 & 2 \\
Total & 84 & 249 & 135 & 87 & 119 & 123 & 500 & 288 \\
\hline
\end{tabular}

Fonte: CREMESP. 
investigação de uma denúncia proposta aos Conselhos Regionais de Medicina, é um forte indicativo do movimento de reclamações que foram apresentadas pelo público em geral, no tocante a uma demanda pretensamente reconhecida como de responsabilidade objetiva pela não-realização do resultado pretendido pela parte.

Não pretende-se afirmar que estes processos serão todos considerados favoráveis aos demandantes, mas, sem dúvidas, a maioria deles, se não a totalidade, irá também gerar uma demanda na esfera jurídica.

Pode-se observar, como exemplo, o Acórdão da Terceira Turma, do Superior Tribunal de Justiça, datado de 13 de abril de $1999^{5}$ :

"Ementa: Civil e processual - cirurgia estética ou plástica - obrigação de resultado (responsabilidade contratual ou objetiva) - indenização - inversão do ônus da prova.

I - Contratada a realização da cirurgia estética embelezadora, o cirurgião assume obrigação de resultado (responsabilidade contratual ou objetiva), devendo indenizar pelo não-cumprimento da mesma, decorrente de eventual deformidade ou de alguma irregularidade.

II - Caberá à inversão do ônus da prova.

III - Recurso conhecido e provido.”

Se for imaginado que a jurisprudência é também uma fonte do Direito, então é possível estar frente a uma norma que pode, e deve, ser seguida de maneira objetiva, sem a análise de que as denominações "estética" e "embelezadora" guardam um forte aspecto subjetivo em seus conceitos.

Da mesma forma, a decisão do TAPR - $6^{\text {a }}$ Câmara Cível ${ }^{6}$ traz que: “(...) Em se tratando de cirurgia plástica o que importa é o resultado e que se este poderia ser alterado por questões outras que independessem da atuação do médico, como é o caso da cicatrização, o paciente deveria ter sido amplamente informado das chances de superveniência de resultado indesejado, sendo que ao médico é quem deveria provar que se desincumbiu deste dever".

\section{DISCUSSÃO}

A consideração de que uma ação que cause dano impõe a necessidade de reparação do valor do dano provocado é algo adequado e arraigado no pensamento do cotidiano jurídico.

Da mesma forma, a Responsabilidade Civil, quer seja objetiva como subjetiva, é bem fundamentada e reconhecida em várias leis e outras fontes do Direito.

$\mathrm{O}$ que se torna menos impreciso é que as diferenças entre a Responsabilidade Civil Subjetiva, determinada por culpa, e a Objetiva, que não necessita desta comprovação, ainda estão se estabelecendo na sociedade em geral e na comunidade jurídica, em especial.

O CDC, em seu Artigo 14, §4, define adequadamente a forma de responsabilidade civil do médico, ou seja, subjetiva. Porém, o dia a dia gera modificações sociais e, desta maneira, também alterações no âmbito do Direito. Isto se deve ao fato de que os promotores do direito também vivem na comunidade e sofrem interferências das suas vivências diárias e dos seus olhares humanos.

Assim, apesar do que foi descrito nos códigos, do apregoado pela academia de que não se pode garantir um resultado ao ato médico, nem mesmo quando se trata de tornar alguém belo, cada vez mais a jurisprudência traz ao nosso cotidiano a notícia de que houve uma modificação no conceito de responsabilidade civil.

Como considerar algo subjetivo como a beleza, discutido ao longo da história e ainda sem definição adequada, em algo objetivo como um resultado estético? Como conseguir que alguém acredite na realização de algo tão inatingível, como a fé e a esperança, sem que seja por meios espirituais ou ilícitos ${ }^{7}$ ?

Em tempos atuais em que, cotidianamente, os meios de comunicação apresentam informes sobre estética, embelezamento e "máquinas miraculosas" operadas por não-médicos, mas "induzindo" que estes seriam procedimentos exclusivamente médicos com a responsabilidade destes profissionais, deve-se observar criteriosamente cada tipo de promessa e profissional envolvido.

Na grande maioria, a responsabilidade pela transformação dos conceitos jurídicos e sociais não é de outro que não do próprio profissional médico, o qual em sua ignorância, ou esperteza, utiliza-se dos recursos da sociedade moderna e induz a população em geral e advogados e juízes, em particular, de que existe esta relação contratual.

A simples apresentação de um modelo fotográfico ou ainda de resultados maravilhosos, como os 
famosos "antes e depois", fotos exibidas de maneira maquiada ou não, consequência de um trabalho executado, fazem com que se criem os laços da relação e, portanto, a assertiva do resultado.

\section{CONSIDERAÇÕES FINAIS}

Vedados pelos Conselhos de Medicina e pelas Sociedades de Especialidades, não pelo temor de uma concorrência trazida a público, mas pela inexistência de demonstração científica de que pessoas diferentes terão resultados iguais, tais peças publicitárias trazem ao imaginário do consumidor e do jurista a falsa impressão de que este fato é possível e, apesar de ser algo individual, pode ser coletivizado e transformado em uma verdade quanto a uma área do conhecimento médico. É criada a ideia de que atos humanos, dependentes de ações também humanas como a técnica e o conhecimento, possam fazer algo que a natureza não conseguiu e que possam modificar o humor e as características individuais das pessoas.

É evidente que a ação ocorre em decorrência de inúmeros fatores, muitos dos quais ainda longe da compreensão da própria Medicina.

Desta maneira, a mídia, com o mote de querer trazer o conhecimento ao seu público pensando exclusivamente no poder econômico, e a presença de indivíduos inescrupulosos e gananciosos contribuem para a crença de uma afirmativa equivocada e que é generalizada hoje à área da Estética (médica ou não), amanhã a toda área da Cirurgia Plástica e da Dermatologia e, no futuro, quem sabe, abrangerá toda a área médica.

Deve-se, portanto, combater estes desvios de condutas, informar a sociedade de maneira geral que os resultados estéticos obtidos pelos mais variados métodos não o são por conta das máquinas, mas sim pela observância de técnicas e estudos e que são apenas meios para a obtenção de um eventual melhor resultado.

Ensinar os profissionais de todas as áreas de que a forma adequada para abordar seus clientes deve ser feita sem promessas ou logros, sem imagens de "antes e depois", sem apresentação apenas de bons resultados, pois, se não for desta maneira, todo aquele que agir de maneira dolosa e intentar contra a sociedade poderá ser punido por esta mesma sociedade.

Somente assim será possível ter a certeza de não serão vivenciados dias de não-tranquilidade quanto ao exercício profissional ou, ainda, o desserviço do atendimento médico da população, a qual, contrariamente ao que se pensa, não irá melhorar com este desvio, mas fará com que menos profissionais se arrisquem nestas áreas do conhecimento, como já acontece em outras partes do mundo e, assim, diminuirá os quadros e aumentará os custos da saúde.

Desse modo, será possível viver tranquilo em uma sociedade eivada de cidadãos e não de aproveitadores.

\footnotetext{
ABSTRACT: Whenever an action causes damage to another person and there is causal nexus, that is, when the result seen by the practice of this action is, directly or not, related, the obligation will fit to repay the victim, a referring value to its damage. This normative, Civil Liability, has as bedding the beginning of the guilt, when subjective (which needs an act or omission that finally violates the right of a second person, the damage produced for this act, the responsibility of causality between the act and the damage and, the guilt) and the risk's beginning when objective (which does not need guilt, since is based on the theory of the risk, presuming it, independently to have or not acted with this intention). While Contractual Civil liability, two are the obligations of a professional: of result, that is, to reach definitive objective or end, and of way, that is, the obligation to use all the half ones for its objective achievement. In the Code of Protection and Defense of the Consumer (Law 8,078, of September 11, 1990), the objective responsibility must be used to all the service renders, except the class of liberal professionals, physicians, and lawyers, for carrying through its activities mainly as being of ways and, therefore, be considered subjective. In some situations, Law understands that the Responsibility should be objective, that is, when a result promise is consubstantiates. The advertisements have had the power to evoke these mistaken situations. The main objective of this paper is to show, to Law professionals and, in particularly, to the doctors, which are the phenomena that had created this shunting line of the norm. The Subjective Civil Liability is supported in the Civil Code, its Art.186 and the caption of the Art.927, while the Objective is observed in the Art. 927, only §. Thus, when relating legal literature texts and data from the Regional Medical Counsel of the State of São Paulo how much the advertisements and investigations restored on this citizen, the authors intend to demonstrate the causal relation of this new way of thinking.
}

Keywords: medical civil liability; subjective responsibility; objective responsibility. 


\section{REFERÊNCIAS}

1. Porto MM. O acaso da culpa como fundamento da Responsabilidade Civil. São Paulo: Ajuris, 38/199.

2. Kfouri Neto M. Culpa Médica e ônus da prova: presunções, perda de uma chance, cargas probatórias dinâmicas, inversão do ônus probatório e consentimento informado: responsabilidade civil em pediatria, responsabilidade civil em gineco-obstetrícia. São Paulo: Editora Revista dos Tribunais; 2002. 527 p.

3. Brasil. Código de Proteção e Defesa do Consumidor (Lei 8.078, de 11/09/1990). Edição revisada, atualizada e ampliada; 1998.28 p.
4. Brasil. Código Civil (Lei no. 10.406, de 10/01/2002). São Paulo: Saraiva; 2008. 464 p.

5. Brasil. Resp. 81101/PR - Recurso Especial-1995/0063170-9. Disponível em: www.stj.gov.br.

6. TAPR - 6 Câmara Cível, Apelação Cível 156.986-6, DJE de 15 de setembro de 2000. Disponível em: www4.tj.ce.gov.br.

7. Vazquez Ferreira R. La prueba de la culpa médica. 2 ed. Buenos Aires: Hammurabi; 1993. p. 42.

\section{Endereço para correspondência:}

FERNANDO CORDEIRO

Rua Severo Penteado, 131 - Cambuí

Campinas (SP), Brasil

E-mail: ramos15@superig.com.br. 